\title{
ACCESSORY RIGHT HEPATIC ARTERY AS PRINCIPAL, ARISING FROM PROPER HEPATIC ARTERY /CASE REPORT /
}

\author{
Ludmil M. Veltchev1, Manol A. Kalniev2, Todor A. Todorov3 \\ 1) Fellow, Master's Program in Hepatobiliary Pancreatic Surgery, Henri \\ Bismuth Hepatobiliary Institute, 12-14, avenue Paul Vaillant-Couturier, 94804 \\ Villejuif Cedex \\ 2) Department of Anatomy, Cytology and Histology, University of Medicine, \\ Sofia, Bulgaria \\ 3) Department of Pathology, University of Medicine, Sofia, Bulgaria
}

\section{ABSTRACT:}

The good knowledge for the normal hepatic artery distribution and the possible anatomical variations is significant in liver transplantation in order for the vascularity not to be disturbed and to cause necrosis of the liver parenchyma postoperatively.

Disruption of an anatomical artery variation is uncommon in liver hilum dissection, but non establishment of continuity in time of reconstruction is an important cause for postoperative complications such as acute liver failure and augment morbidity and mortality.

The aim of this case report is to present a non published anatomical variation of accessory right hepatic artery arising from proper hepatic artery between the branching of gastroduodenal artery and bifurcation of the proper hepatic artery to right and left branches.

Key words:

Accessory right hepatic artery, liver transplantation, anatomical variations, significance

\section{INTRODUCTION:}

The early classification of the arterial vascularity of the liver is linked to researches conducted by Michels (1) and Melliere (2) in the 50's of this century. According to the observations $60 \%$ represent classical variation of arterial distribution and $40 \%$ different other anatomical variations. Of interest is also the separate description of the variations of the right hemiliver.

Arterial distribution and anatomical variation become significant after accepting the Liver Transplantation as a routine method of treatment (3). That allows detailed study and description of the variations and of the surgical techniques for repair after succeful procurement (4). When the whole of the arterial branches is disrupted, most of the authors recommend their restoration and if that is not possible, their reconstruction through inosculation with adjacent artery.

\section{Case report:}

Patient init \# 5251603

DOB: $19 / 07 / 2008$

Date of case: 10/05/2008

Operation: Orthotopic deceased donor liver transplantation

In time of backbench preparing of donor liver allograft, we found an accessory right hepatic artery arising from the proper hepatic artery between the branching of the gastro duodenal artery and bifurcation of hepatic artery to right and left branch. This accessory artery arises posterolateraly and enters the hepatoduodenal ligament with parallel way to common hepatic duct.

In Hartman's pouch it passes behind infundibulum of the gallbladder and enters the right hemiliver, in segment $\mathrm{V}$.

The diameter of the accessory artery was nearly 4.5 $\mathrm{mm}$ and two times wider than the principal right branch and we suppose that this artery presents a significant source for supply of the right hemi liver (Fig.1)

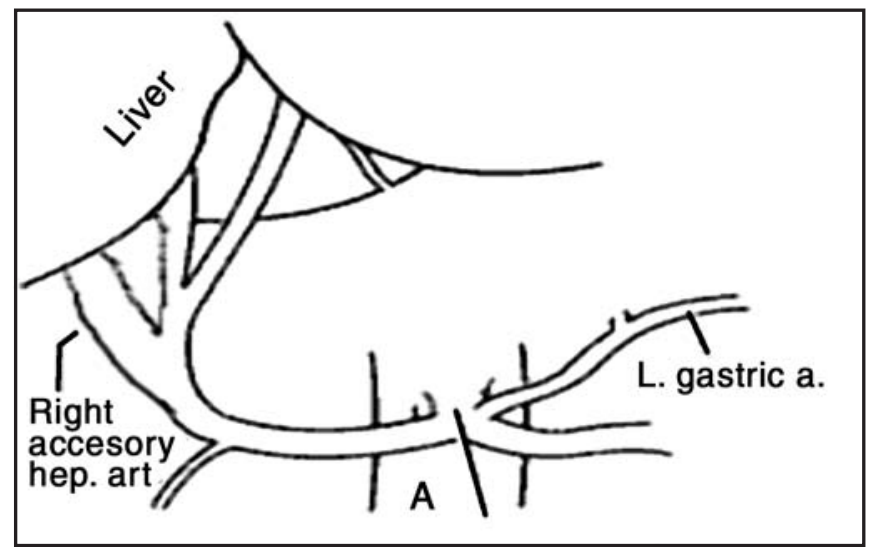

Fig. 1. Right accessory hepatic artery as principal source for right liver lobe 


\section{DISCUSSION}

The anatomy of the hepatic artery (HA) is of great importance in general surgery and in hepatic surgery, especially in liver transplantation (LT), as well as in many radiological procedures such as trans-arterial chemoembolization for hepatic tumors. The vascular anatomy of the liver is variable. Variations have occurred in 25\% to $75 \%$ of cases. The biggest clinical study that was reported in 1994 by Hiatt et all. (6) reported the next classification:

Type 1 - In this normal pattern, the common hepatic artery arose from the celiac axis to form the gastro duodenal and proper hepatic arteries; the proper hepatic artery divided distally into right and left branches.

Type 2 - A replaced or accessory left hepatic artery arose from the left gastric artery.

Type 3 - A replaced or accessory right hepatic artery originated from the superior mesenteric artery.
Type 4 - In this double-replaced pattern, the right hepatic artery arose from the superior mesenteric artery, and the left hepatic artery was a branch of the left gastric artery.

Type 5- The entire common hepatic artery originated as a branch of the superior mesenteric artery.

Type 6- The common hepatic artery took direct origin from the aorta

Donor livers represent an appropriate model for study because extrahepatic arterial anatomy must be defined precisely to ensure complete arterializations of the graft at time of transplantation.

It is important to perform precise dissection of the hepatoduodenal ligament and to save the accessory structure and in particular the arterial supply of the liver. The existence of many described anatomical variations puts the knowledge for them under question. In case of injury precise reestablishment of continuity or new reconstruction with neighbouring artery must be performed.

\section{REFERENCES:}

1. Michels N.A. Blood supply and anatomy of upper abdominal organs with descriptive atlas. J.B.Lippincot Co, edit., Philadelphia, 1955, pp139-163.

2. Melliere D. Topographie artérielle et chirurgie pancréatique. Thèse méd., Paris, 1966.

3. Mlakar B, Gadzijev EM, Ravink D, Hribernik M(2002) Anatomical variations of the arterial pattern in the right hemiliver.Eur. J Morphol. 40: 267-273.

4. E. Chaib, M . Ribeiro Jr., W. Saad, J

- Gama-Rodrigues. The Main Hepatic

Anatomic Variations for the Purpose of

Split -Liver Transplantation.

Transplantation Proceedings, Volume

37, Issue 2, Pages 1063 - 1066.

5. Settemacher U, Haase R, Heise M,
Bechstein WO, Neuhaus P.Variation of surgical reconstruction in liver transplantation depending on vasculature. Langebeck's Arch Surg 384:378-383.

6. J.R. Hiatt J.Gabbay,R W. Busuttil. Surgical Anatomy of the Hepatic Arteries in 1000 Cases. Ann Surg.1994 Vol. 220, No. $1,50-52$

\section{Corresponding author:}

Ludmil Marinov Veltchev, MD, PhD

E-mail: drlmarinov@yahoo.com 